\title{
Towards to Flow State Identification in Educational Games: An Empirical Study
}

\author{
Wilk Oliveira dos $\operatorname{Santos}^{1}$, Tancicleide Carina Simões Gomes ${ }^{2}$, Célia Cristina Vilela da \\ Silva $^{3}$ \\ ${ }^{1}$ Center of Excellence for Social Technologies (NEES) - Computer Institute (IC) - Federal \\ University of Alagoas (UFAL) - Maceió, AL - Brazil \\ ${ }^{2}$ Center of Informatics (CIn) - Federal University of Pernambuco (UFPE) - Recife, PE - Brazil \\ ${ }^{3}$ University of Pernambuco (UPE) - Garanhuns, PE - Brazil \\ wos@ic.ufal.br, \{tancicleide.gomes, celinhacristina20\}@gmail.com
}

\begin{abstract}
Flow Theory has been discussed in several aspects in the last decades, in different domains, such as work, social life, and educational technologies, among others. Particularly in the field of educational games, a series of discussions have been conducted in the academic, for instance, the importance to design activities to lead students to flow state and identify students' flow experience during educational games. This study has conducted an experiment in order to identify the students' flow experience in 19 Brazilians elementary school students using a flow state scale specific to the field of educational games. The main results indicate the flow state scale was capable of measure the students' experience, however, most of the students did not reach the complete flow experience during the game.
\end{abstract}

\section{Introduction}

In the last decades, the international industry of game development has been increasing, becoming an important worldwide industry. According to a recent report of Entertainment Software Association (ESA 2015), only in the United States, there are approximately 155 million of players moving, in 2014, approximately $\$ 22.41$ billion around the word. Additionally, another interesting recent study showed that $74 \%$ of $K-8^{1}$ teachers use digital games in the classroom (Lofgren 2015), enabling a considerable growth of the educational games industry in the last years.

In the academic context, a series of recent studies have been done in order to investigate effects of video games in different educational aspects (e.g. Anderson et al. (2010), Scoresby and Shelton (2011), Oliveira et al. (2015) and others). These studies have highlighted a series of discussions related to video games positive effects in student's learning, such as game fullness, motivation, and flow experience; and negative effects, such as: violence, social interaction absence and extreme appreciation of "digital" (digital activities conducted using some kind of technological device), in detriment to "traditional" (traditional (physical/ manual) activities).

\footnotetext{
${ }^{1}$ K-8 schools are schools in the United States that enroll students from kindergarten/pre-K (age 5) through 8th grade (up to age 14), combining the typical elementary school (K-5) and junior high or middle school (6-7-8).
} 
Enthusiasm, engagement, and motivation seem to be keywords when dealing with complex activities that demand a considerable amount of effort and dedication - the learning activity, for instance. On the other hand, a research conducted by Getúlio Vargas Foundation in 2009, says $40 \%$ of students between 15 and 17 years drop out because they find the school uninteresting - in other words, they fail to be motivated for proposed activities in school. This situation highlights the importance of developing and uses educational games capable of increasing students' engagement, motivation, and flow, aiming to increase students' learning.

Based on that, one of the main challenges of Flow Theory applied to Computers and Education is to identify students' flow experience during their activities (Santos et al. (2015)), especially, in educational games. This study conducted an experiment in aiming to identify the students' flow experience in a group of 19 Brazilians elementary school students from a public school, using the flow state scale (FSS) EGameFlow (Fu et al. 2009), famous FSS capable of measuring students' flow state and learning during educational games.

The main results of the experiment indicate the FSS is capable of measure the students' experience during the game, inclusive, the learning experience. The game used in the experiment was capable of providing some of the flow experience dimensions (e.g. goal clarity and concentration), however, failed in others flow dimensions (e.g. autonomy and immersion). Moreover, the FSS also indicate the game improve the knowledge of some students.

\section{Background}

In this section, we present the main topics addressed in this study: educational games and flow theory and its main concepts, as well as some related works.

\subsection{Educational Games}

Over the last 20 years, computer games have been increasingly replaced the more traditional games as leisure activities, and have had a transformational impact on how we spend our leisure time (Connolly et al. 2012). According to these authors, educational games provide engaging activities and it seems like that, far from waning, interest in games for leisure is still growing.

At this point, in the last decades, educational games have been used in many teaching contexts of different topics as: Business, Geography, History, and others (Connolly et al. 2012), as well as studied in different perspectives as violence (Anderson and Gentile 2014), learning (Linehan et al. 2014), playfulness (Scoresby and Shelton 2011) and others.

According to recent studies, a series of empirical results related to games-based learning has shown that despite the overwhelming publicity given to the negative impact of games, like most technologies before them, computer games can have both positive and negative impacts (Connolly et al. 2012). These results are important to demonstrate not only the efficacy of games in an educational context but also to highlight the importance of new studies in different kind of educational games, for instance, identify if is capable of providing flow experience for the players. 


\subsection{Flow Theory}

The notion of "flow state" was introduced by Csikszentmihalyi (1975) as a technical term to describe a good feeling or "optimal experience" that people have as a motivating factor in their daily activities, such as at work, sports, and artistic performance (Faiola et al. 2013). According to this author, the key to understanding flow state is the "autotelic experience" concept (from the ancient Greek $\alpha \hat{\tau} \tau \tau \varepsilon \lambda \eta \dot{\zeta}$, or "self-goal"). Autotelic experience is the result of an activity or situation that produces its own intrinsic motivation, rewards, or incentives, specifically without any outside goals or rewards.

Since the establishment of the basis of Csikszentmihalyi's Flow Theory, several approaches have been presented in order to describe this kind of experience. Csikszentmihalyi (1990) describes nine necessary dimensions in order for an activity to prompt a flow state: (1) clear goals; (2) immediate feedback; (3) a match between personal skills and challenges; (4) merger of action and awareness; (5) facilitate concentration on the task, (6); aid a sense of control; (7) loss of self-consciousness during the task; (8) sense of time changed; and (9) the experience of becoming "autotelic".

Hoffman and Novak (1996) summarized the dimensions proposed by Csikszentmihalyi into five dimensions: (1) enjoyment; (2) telepresence; (3) focused attention; (4) engagement; and (5) time distortion. On the other hand, RodriguezSanchez and Schaufeli (2008) stated that the previous dimensions could be simplified into just three key aspects: (1) absorption, (2) enjoyment, and (3) intrinsic interest.

In order for an activity to lead an individual to flow state, it should provide a balance between challenge's level and ability required for the person to complete the activity. If the difficulty of a challenge is greater than the person's skill level, he/she gets anxious. By contrast, if the difficulty of the challenge is lesser than the person's ability, it tends to be a boring activity (Admiraal et al. 2011).

\subsubsection{Flow Models}

Over the time, different conceptual models have been proposed in order to describe flow state. These models established parameters to measure flow state level, through flow state scales and others instruments. Csikszentmihalyi (1975) was the first researcher to propose a model to describe flow state. He proposed the flow as an emotional state located between anxiety/arousal and relaxation/control. In the first model, Csikszentmihalyi describes flow as an emotional state that people can feel during specific activities, especially, activities that provide a balance between people skill level and activity challenge level and immediate feedback.

Some years later, new researches have been conducted and new models have been proposed ${ }^{2}$. Csikszentmihalyi proposed a new model based on the first one, which represents a simplification model, synthesizing the skill-challenge balance to flow state. Afterward, others researchers proposed different flow models and representations (all based on the Csikszentmihalyi's flow models). Schell (2014) proposed a slightly different model on which flow state can vary in each people and the flow state level can

\footnotetext{
${ }^{2}$ Flow models present in section 2.1.1: $\underline{\text { https://goo.gl/1GzlAc }}$
} 
be bigger or smaller at different times of the activity. More recently, Sala (2013) addressed flow state by dividing it into different modules (worlds), on which each state is located in a different slice of time. Furthermore, Massimini and Carli (1988) proposed a flow model that separates the flow components in different channels. In the second footnote is possible to access the flow models before presented.

\subsubsection{Flow State Scales}

A measurement of flow state has also been addressed in the last decades. Indeed, a series of methods have been proposed in order to identify and measure flow state levels. Jackson and Marsh (1996) proposed the FSS, which is a technique to measure flow state of people in different activities, for instance: sport, physical educational activities, and others. An FSS is generally composed of questions related to different flow dimensions, such as clear goals, immediate feedback, a match between personal skills and challenges, and others.

As a result of such scale, several studies have implemented different FSSs. It is composed of 36 items, representing the nine flow dimensions proposed by Csikszentmihalyi. More recently, Yoshida et al. (2013) proposed an FSS in order to measure flow state level in an occupational task. This FSS is composed of 14 items and based on the nine flow dimensions proposed by Csikszentmihalyi. Another proposal was made by Novak et al. (2000), which measured the flow state level in online environments. Martin and Jackson (1996) proposed other FSS in order to evaluate the subjective experience of flow through two brief measures of flow.

Finally, some FSSs have also been developed in order to measure flow state in educational games. Fu et al. (2009) and Kiili et al. (2012) proposed scales for it. The former proposed the EGameFlow, composed of 42 items and with eight flow dimensions (Concentration, Clear Goal, Feedback, Challenge, Autonomy (control), Immersion, Social Interaction and Knowledge Improvement). The later proposed the scale by taking into account nine dimensions of flow (challenge, goal, feedback, playability, concentration, time distortion, rewarding experience, loss of selfconsciousness, and sense of control). The FSS EGameFlow (Fu et al. 2009) was adopted in our study, for being one of the most commonly FSS to measure students' flow state in educational games, as well, for being empirically evaluated in a real scenario.

\subsection{Related Works}

In the last years, some researchers have started studies regarding flow theory applied and educational games. Kiili et al. (2012) were one of the first to conduct studies in this domain, proposing a framework in order to provide principles for good educational game design, based on associative, cognitive and learning theories, to lead students to flow. The main results indicate that a flow framework is a useful tool in studying game-based learning experiences.

This study was one of the first conducted in this field, however, the study scope is to provide a framework to lead students to flow and do not take into account the game' evaluation in terms of flow, highlighting the importance of identifying if the game is capable of leading students to flow, as well, to associate the flow experience with the student's learning. 
In a more recent study conducted by Hong et al. (2013) was measured the student's flow experience in a Heart Attack game with a sample of 209 5th and 6thgrade elementary school students. Results indicated that in terms of flow experiences, Heart Attack group was significantly higher than that of the Solitary group; secondly, the solitary game showed a better retention rate than Heart Attack game did after one month; even though the retention rate of both type games has slight loose after one month.

This study was important to highlights the importance of measure the student's flow state level in educational games, however, the study did not use an FSS empirically evaluated, creating an own scale based on only three flow dimensions defined by Pearce, Ainley, and Howard (2005), making it difficult more deep analysis on the results and showing the importance of to conduct new studies in this field.

More recently, Hou (2015) conducted a study using an integrated method of sequential analysis and cluster analysis and explored the learners' flow state and learning behavioral patterns. This work identified a wide variety of learning behavior patterns from three potential clusters of learners, and the different levels of flow experienced by the learners affected their learning behavior patterns; learners with higher levels of flow demonstrated a more in-depth reflective process.

This study provides important initial results, showing that is possible the flow experience increase student's learning. However, it also did not use a comprehensive FSS specific to measuring student's flow experience in educational games, highlighting the importance of conduct more deep research on flow theory and educational games. One of the main comparative highlights of our study is to investigate the flow experience in educational games based on an empirical FSS capable of correlating the students' flow experience with their learning, with a real game in a real scenario.

\section{Experiment}

The experiment was conducted following the Goal Question Metrics (GQM) (Wohlin et al. 2012). The experiment is a quantitative experiment aiming to measure the students' flow experience and learning during the use of an educational game to the Mathematics teaching.

\subsection{Method}

The experiment was executed through the user report method. In this method the evaluation is conducted through the students' report about some intent (in this case, educational game).

\subsection{Participants}

The participants were $N=19$ (11 males, seven females and one chose not to report) elementary school students, from a Brazilian public school. The average age of students was 14 years old.

\subsection{Execution of Experiment}

In the first step, students were invited to participate in the experiment, an agreement letter was invited to the students' parents, explain about the experiment. In the second 
VI Congresso Brasileiro de Informática na Educação (CBIE 2017)

Anais do XXVIII Simpósio Brasileiro de Informática na Educação (SBIE 2017)

step, the students who agreed to participate in the experiment were invited to play an educational game during 20 minutes. The game ${ }^{3}$ is composed of ten steps and was developed based on a specific methodology to develop educational games (see Santos and Silva Junior 2016). In the third step, the students were invited to answer the EGameFlow scale, according to their experience during the game.

\subsection{Results and Discussion}

The results were collected and organized individually by each question of the FSS used in the experiment and categorized according to each flow theory dimension. Three metrics were used (mean, median and mode). The questions G1, G2, G3, and G4 coincidentally from the second flow theory dimension (goal clarity) obtained a better evaluation by the students, with the mean 5.79, 5.32, 5.26 and 5.05 respectively. The dimension "concentration" also presented a high mean on the students' evaluation. These results indicate the game presented goal clarities, important flow experience dimension, as well as, the students presented a high level of concentration during the game. Table 1 present the results obtained in each question of EGameFlow scale, organized in categories.

\begin{tabular}{|c|c|c|c|c|c|}
\hline Factor & Ref. & Content & Mean & Median & Mode \\
\hline \multirow{6}{*}{ 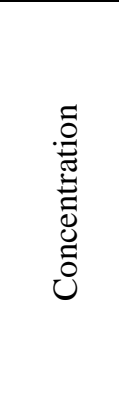 } & $\mathrm{C} 1$ & $\begin{array}{l}\text { Most of the gaming activities are related to the } \\
\text { learning task }\end{array}$ & 4.68 & 5 & 7 \\
\hline & $\mathrm{C} 2$ & No distraction from the task is highlighted & 4.68 & 5 & 7 \\
\hline & $\mathrm{C} 3$ & $\begin{array}{l}\text { Generally speaking, I can remain concentrated in the } \\
\text { game }\end{array}$ & 3.84 & 4 & 1 \\
\hline & $\mathrm{C} 4$ & $\begin{array}{l}\text { I am not distracted from tasks that the player should } \\
\text { concentrate on }\end{array}$ & 4.16 & 4 & 3 \\
\hline & $\mathrm{C} 5$ & I am not burdened with tasks that seem unrelated & 4.26 & 5 & 7 \\
\hline & C6 & Workload in the game is adequate & 4.16 & 4 & 4 \\
\hline \multirow{4}{*}{$\begin{array}{l}\stackrel{\vec{E}}{\vec{E}} \\
\frac{\tilde{U}}{\tilde{0}} \\
\stackrel{0}{0}\end{array}$} & G1 & $\begin{array}{l}\text { Overall game goals were presented in the beginning } \\
\text { of the game }\end{array}$ & 5.79 & 7 & 7 \\
\hline & $\mathrm{G} 2$ & Overall game goals were presented clearly & 5.32 & 6 & 7 \\
\hline & G3 & $\begin{array}{l}\text { Intermediate goals were presented in the beginning of } \\
\text { each scene }\end{array}$ & 5.26 & 6 & 7 \\
\hline & G4 & Intermediate goals were presented clearly & 5.05 & 6 & 7 \\
\hline \multirow{5}{*}{ 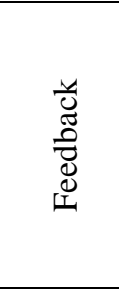 } & F1 & I receive feedback on my progress in the game & 4.63 & 5 & 7 \\
\hline & $\mathrm{F} 2$ & I receive immediate feedback on my actions & 4.42 & 4 & 4 \\
\hline & F3 & I am notified of new tasks immediately & 3.58 & 4 & 1 \\
\hline & F4 & I am notified of new events immediately & 3.42 & 4 & 1 \\
\hline & F5 & $\begin{array}{l}\text { I receive information on my success (or failure) of } \\
\text { intermediate goals immediately }\end{array}$ & 4.63 & 4 & 4 \\
\hline \multirow{3}{*}{ 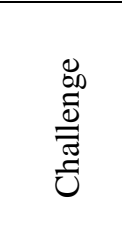 } & H1 & $\begin{array}{l}\text { The game provides "hints" in text that help me } \\
\text { overcome the challenges }\end{array}$ & 3.89 & 4 & 7 \\
\hline & $\mathrm{H} 2$ & $\begin{array}{l}\text { The game provides "online support" that helps me } \\
\text { overcome the challenges }\end{array}$ & 3.68 & 4 & 1 \\
\hline & $\mathrm{H} 3$ & $\begin{array}{l}\text { The game provides video or audio auxiliaries that } \\
\text { help me overcome the challenges }\end{array}$ & 3.58 & 4 & 1 \\
\hline
\end{tabular}

\footnotetext{
${ }^{3}$ The game used in this study can be accessed by this link: http://migre.me/wJBUg
} 
VI Congresso Brasileiro de Informática na Educação (CBIE 2017)

Anais do XXVIII Simpósio Brasileiro de Informática na Educação (SBIE 2017)

\begin{tabular}{|c|c|c|c|c|c|}
\hline & $\mathrm{H} 4$ & $\begin{array}{l}\text { The difficulty of challenges increase as my skills } \\
\text { improved }\end{array}$ & 4.79 & 6 & 7 \\
\hline & H5 & $\begin{array}{l}\text { The game provides new challenges with an } \\
\text { appropriate pacing }\end{array}$ & 4.05 & 4 & 7 \\
\hline & H6 & $\begin{array}{l}\text { The game provides different levels of challenges that } \\
\text { tailor to different players }\end{array}$ & 4.47 & 4 & 4 \\
\hline \multirow{3}{*}{ 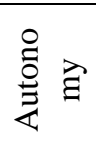 } & A1 & I feel a sense of control and impact over the game & 3.53 & 4 & 1 \\
\hline & A2 & I know next step in the game & 3.79 & 4 & 4 \\
\hline & A3 & I feel a sense of control over the game & 3.47 & 4 & 3 \\
\hline \multirow{7}{*}{ 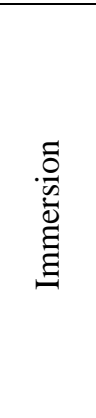 } & $\mathrm{I} 1$ & I forget about time passing while playing the game & 3.79 & 4 & 1 \\
\hline & $\mathrm{I} 2$ & $\begin{array}{l}\text { I become unaware of my surroundings while playing } \\
\text { the game }\end{array}$ & 4.21 & 4 & 7 \\
\hline & $\mathrm{I} 3$ & $\begin{array}{l}\text { I temporarily forget worries about everyday life while } \\
\text { playing the game }\end{array}$ & 4.11 & 4 & 1 \\
\hline & I4 & I experience an altered sense of time & 4.32 & 4 & 4 \\
\hline & I5 & I can become involved in the game & 3.21 & 3 & 1 \\
\hline & I6 & I feel emotionally involved in the game & 3.26 & 2 & 1 \\
\hline & $\mathrm{I} 7$ & I feel viscerally involved in the game & 2.95 & 3 & 1 \\
\hline \multirow{6}{*}{ 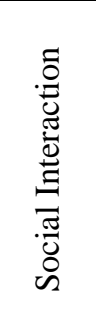 } & S1 & I feel cooperative toward other classmates & 4.05 & 4 & 1 \\
\hline & $\mathrm{S} 2$ & I strongly collaborate with other classmates & 4.37 & 4 & 7 \\
\hline & S3 & The cooperation in the game is helpful to the learning & 4.53 & 4 & 7 \\
\hline & $\mathrm{S} 4$ & $\begin{array}{l}\text { The game supports social interaction between players } \\
\text { (chat, etc) }\end{array}$ & 2.95 & 3 & 1 \\
\hline & S5 & The game supports communities within the game & 3.21 & 4 & 1 \\
\hline & S6 & The game supports communities outside the game & 3.26 & 4 & 1 \\
\hline \multirow{5}{*}{ 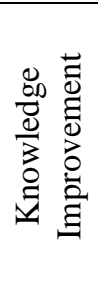 } & K1 & The game increases my knowledge & 4.42 & 4 & 7 \\
\hline & $\mathrm{K} 2$ & I catch the basic ideas of the knowledge taught & 4.05 & 4 & 4 \\
\hline & K3 & I try to apply the knowledge in the game & 4.79 & 5 & 7 \\
\hline & K4 & $\begin{array}{l}\text { The game motivates the player to integrate the } \\
\text { knowledge taught }\end{array}$ & 3.95 & 4 & 4 \\
\hline & K5 & I want to know more about the knowledge taught & 2.58 & 3 & 1 \\
\hline
\end{tabular}

Table 1. Flow experience measurement

On the other hand, the questions I7, I5 and I6, from the immersion dimension, presented a low level on the students' evaluation (2.95, 3.21 and 3.26 respectively). At the same time, the "autonomy" dimension also receive a low evaluation from the students $(\mathrm{A} 1=3.53, \mathrm{~A} 2=3.79$ and $\mathrm{A} 3=3.47)$. These results indicate the students were not immersed in the game nor could they use their autonomy during the game. The knowledge improvement, also measured by the scale, presented a good evaluation in four of the five questions of this category $(\mathrm{K} 1=4.42, \mathrm{~K} 2=4.05, \mathrm{~K} 3=4.79$ and $\mathrm{K} 4=3.95)$. The result indicate despite the game not provide high level in all of flow dimensions category, was able to improve the students learning.

In summary, is possible to perceive not all flow dimensions were achieved for the students, and the flow experience was not complete. On the other hand, the game was effective on students' learning. The FSS used in the experiment was effective to measure the students' flow experience. These results indicate that the game is fit to start to be user with students; however some aspects of game design need to be reviewed in order to improve the aspects bad evaluated in our experiment. 


\section{Threats to Validate}

This section describes concerns that must be improved in future replications of this study and other aspects that must be taken into account in order to generalize the results of the evaluation performed in this section. In general, the design of the evaluation aimed at minimizing a lot of the threats discussed in this section. To organize this section, the threats to validity were classified using the Internal, External, Construct and Conclusion categories (Wohlin et al., 2012).

Internal: As the experiment involves the active participation of humans, it was also prone to a number of internal threats, such as $(i)$ history - it is possible that the moment at which the experiment occurred may have affected the results, however, this threat was minimized by letting participants participating in the experiment without interference of other students and their teachers; (ii) maturation - since the participants used the game during more than 20 minutes to answer the questionnaire, and the students responded the survey more than one time during the experiment, it is possible that they were bored or tired while answering the survey; and (iii) positive bias - as this experiment is not paired (i.e., subjects only analyze one treatment (e.g., version 1)), it is likely that participants did not have a basis for comparison with other educational games.

External: The participants of the experiment are representative only for the scholar context. In particular, as previously described, participants were high schools students from one research groups. In this way, we might not be able to generalize the results of this experiment to other contexts. The subjects of this evaluation should be broadened to other academic settings to obtain more generic results.

Construct: The threats of this category are mainly related to two aspects of our experiments. This experiment measures many different items from different aspects, and some constructs may not be measured by the questions. To minimize these threats we selected, methodologies and instruments empirically validated and used commonly used in the scientific empirical studies from the community of computers and education.

Conclusion: The threats related to this category concern of conclusion of experiment and writing of results. The game was played in the web version using personal computers from the school were de experiment was executed. During the execution of the experiment, the game presented few executions problems, thus, maybe these problems have affected the player's experience. The sample of the experiment may have been short to obtain deep conclusions about the results and can be replicated with more students to more in-depth results.

\section{Concluding Remakes}

One of the main challenges of flow theory applied to computers and education is to identify the students' flow state during their educational activities, for instance in educational games (Santos et al. 2016). This study has conducted an experiment in order to identify students' flow experience in an educational game to mathematics teaching 
VI Congresso Brasileiro de Informática na Educação (CBIE 2017)

Anais do XXVIII Simpósio Brasileiro de Informática na Educação (SBIE 2017)

using an FSS specially develop to measure students' flow state and learning in educational game.

The main results indicate the scale used was effective to identify the students experience during the game. The game used in the experiment was effective for the most students in some flow state dimensions, however, was not effective in others dimensions, indicating the game was not capable of to lead students to a complete flow experience.

As future studies, we aim to replicate the experiment in different educational games for different domains, for instance, Language, Biology, Chemistry, and others. We also aim as future study provide new studies in order to identify the relationship between some flow dimensions, for instance, the relationship between feedback, immersion, and learning, as well, a more deep analysis about the individual students experience.

\section{References}

Admiraal, W., Huizinga, J., Akkerman, S., \& Ten Dam, G. (2011) "The concept of flow in collaborative game-based learning". In: Computers in Human Behavior, 27(3), 1185-1194.

Anderson, C. A., \& Gentile, D. A. (2014). Violent Video Game effects on Aggressive thoughts, feelings, physiology, and Behavior. Media Violence and Children: A Complete Guide for Parents and Professionals, 229.

Connolly, T. M., Boyle, E. A., MacArthur, E., Hainey, T., \& Boyle, J. M. (2012). A systematic literature review of empirical evidence on computer games and serious games. Computers \& Education, 59(2), 661-686.

Csikszentmihalyi M. (1990) "Flow: The psychology of optimal experience”. New York: Harper-Collins.

Csikszentmihalyi, M. (1975) "Beyond boredom and anxiety". Jossey-Bass Publishers. pp. 10 ISBN 978-0-7879-5140-5. Retrieved 10 July 2015.

Faiola, A., Newlon, C., Pfaff, M., \& Smyslova, O. (2013) "Correlating the effects of flow and telepresence in virtual worlds: Enhancing our understanding of user behavior in game-based learning". Computers in Human Behavior, 29(3), 1113-1121.

Fu, F. L., Su, R. C., \& Yu, S. C. (2009). EGameFlow: A scale to measure learners' enjoyment of e-learning games. Computers \& Education, 52(1), 101-112.

Hoffman, D. L., \& Novak, T. P. (1996) "Marketing in hypermedia computer-mediated environments: Conceptual foundations". Journal of Marketing, 60(2), 50-68.

Hong, J. C., Hwang, M. Y., Chen, W. C., Lee, C. C., Lin, P. H., \& Chen, Y. L. (2013). Comparing the retention and flow experience in playing Solitary and Heart Attack games of San Zi Jing: A perspective of Dual Process Theory. Computers \& Education, 69, 369-376.

Hou, H. T. (2015). Integrating cluster and sequential analysis to explore learners' flow and behavioral patterns in a simulation game with situated-learning context for 
VI Congresso Brasileiro de Informática na Educação (CBIE 2017)

Anais do XXVIII Simpósio Brasileiro de Informática na Educação (SBIE 2017)

science courses: A video-based process exploration. Computers in human behavior, $48,424-435$.

Jackson, S. A., \& Marsh, H. W. (1996). Development and validation of a scale to measure optimal experience: The Flow State Scale. Journal of sport and exercise psychology, 18, 17-35.

Kiili, K., de Freitas, S., Arnab, S., \& Lainema, T. (2012). The design principles for flow experience in educational games. Procedia Computer Science, 15, 78-91.

Linehan, C., Bellord, G., Kirman, B., Morford, Z. H., \& Roche, B. (2014, October). Learning curves: analyzing pace and challenge in four successful puzzle games. In Proceedings of the first ACM SIGCHI annual symposium on Computer-human interaction in play (pp. 181-190). ACM.

Massimini, F., \& Carli, M. (1988). The systematic assessment of flow in daily experience.

Novak, T. P., Hoffman, D. L., \& Yung, Y. F. (2000). Measuring the customer experience in online environments: A structural modeling approach. Marketing science, 19(1), 22-42.

Oliveira, W., Neto, S., da Silva Junior, C. G., \& Bittencourt, I. I. (2015, October). Avaliação de Jogos Educativos: Uma Abordagem no Ensino de Matemática. In Brazilian Symposium on Computers in Education (Vol. 26, No. 1, p. 657) (in Portuguese).

Pearce, J. M., Ainley, M., \& Howard, S. (2005). The ebb and flow of online learning. Computers in human behavior, 21(5), 745-771.

Rodriguez-Sanchez, A. M., \& Schaufeli, W. B. (2008) "Flow experience among information and communication technology user". Psychological Reports, 102, 2939.

Sala, T. (2013) "Game Design Theory Applied: The Flow Channel". Available on the Internet at <http://tinyurl.com/SalaFlowApplied > . Accessed May, 19th, 2015.

Santos, W. O., Bittencourt, I. I., Isotani, S., Silveira, F. I., \& Marques, L. B. (2015). Challenges of Flow Theory Applied to Computers in Education. In IV Workshop of Challenges of Computer in Education. Recife-PE, Brazil.

Santos, W. O.; da Silva, A. P.; Silva Junior, C. G. (2014) "Conquistando com o Resto: Virtualização de um Jogo para o Ensino de Matemática”. In: Anais do Simpósio Brasileiro de Informática na Educação (SBIE). p. 317-321 (in Portuguese).

Schell, J. (2014). The Art of Game Design: A book of lenses. CRC Press.

Scoresby, J., \& Shelton, B. E. (2011). Visual perspectives within educational computer games: effects on presence and flow within virtual immersive learning environments. Instructional Science, 39(3), 227-254.

Yoshida, K., Asakawa, K., Yamauchi, T., Sakuraba, S., Sawamura, D., Murakami, Y., \& Sakai, S. (2013). The flow state scale for occupational tasks: development, reliability, and validity. Hong Kong Journal of Occupational Therapy, 23(2), 54-61. 